\title{
FOREWORD
}

\section{Diagnostic and Treatment Issues of Apraxia}

The disorder "apraxia of speech" (AOS) has been a subject of some controversy during the 30 or so years since Frederick Darley and his colleagues at the Mayo Clinic first described it, particularly with regard to its distinction from aphasia syndromes such as Broca's aphasia and the pure articulatory impairment called "aphemia."

Interestingly, the schools of thought regarding AOS have had a rather regional bias in the United States. Those trained in the "Boston" tradition of aphasia classification (as delineated by Norman Geschwind and Harold Goodglass) tend to believe that the term "apraxia" should be reserved for disorders of purposeful movement that are not specific to language (e.g., limb apraxia, buccofacial apraxia). Furthermore, they argue that many of the speech behaviors described in association with AOS can be explained on a linguistic basis. Those trained by Darley and his colleagues and their students at the Mayo Clinic in Minnesota accept AOS as a disorder that can exist in a pure form, although it often accompanies aphasia.

The issue of accurate diagnosis is of great importance to rehabilitation in so far as any diagnosis implies a certain understanding of the underlying nature of the disorder. For example, it is known that "naming" problems are a core symptom of aphasia. The approach to treating word-retrieval problems may differ, however, according to the form of aphasia. For example, using a serial-stage, cognitive model of nam- ing, a person with anomic aphasia may have greater deficits in the semantic system than the person with Wernicke's aphasia, whose deficits are mainly at the level of the phonological lexicon. It is also the case that many speechlanguage disorders are associated with distinct lesion sites. This knowledge is important to neurobehavioral treatment approaches based on spared and impaired brain regions and pathways such as Alexander Luria's intersystemic and intrasystemic reorganization methods.

Trained as I am in the "Boston" school of thought, my understanding of AOS was "fuzzy" because AOS was never used to describe the individuals seen in our clinical service. Yet, I think it is important for all of us to understand this disorder because it is frequently diagnosed by speech-language pathologists who choose treatment approaches in accordance with this diagnosis. Some individuals who have been referred to our clinic with diagnoses of "apraxia" (which we assume means "apraxia of speech") have been treated accordingly for sound production problems. These same individuals may then be diagnosed as having Broca's aphasia and treated for language problems.

With all these considerations in mind, it seemed time to dedicate an issue of Seminars in Speech and Language to the topic of apraxia of speech. I could think of no better person to serve as Guest Editor for this issue than Dr. Malcolm McNeil. Dr. McNeil has been a leading investigator of this disorder and has writ-

Apraxia of Speech: From Concept to Clinic. Editors in Chief, Nancy Helm-Estabrooks, Sc.D., and Nan Bernstein Ratner, Ed.D.; Guest Editor, Malcolm R. McNeil, Ph.D. Seminars in Speech and Language, volume 23, number 4, 2002. ${ }^{1}$ Aphasia Research Center, Boston VA Healthcare System, Boston, Massachusetts. Copyright (C) 2002 by Thieme Medical Publishers, Inc., 333 Seventh Avenue, New York, NY 10001, USA. Tel: +1(212) 584-4662. 0734-0478,p;2002,23;04, 219,220,ftx,en;ssl127a. 
ten extensively and in great depth about it. $\mathrm{He}$ is also part of an international community of scientific and clinical researchers pursuing this line of study. I am most grateful that he agreed to take on the task of putting this issue together and that he was able to recruit such a prestigious group of contributors.

Here, then, is an issue of Seminars directed at students and clinicians who have questions about AOS: what it is, what causes it, how to recognize it, and how to treat it. I have learned a great deal about AOS in the process of reading and editing the papers. It has helped enormously in overcoming the "regional" bias of my training. I think that other readers will find it highly educational and that it has good clinical applicability.

Nancy Helm-Estabrooks, Sc.D. Co-Editor in Chief ${ }^{1}$ 